\title{
Ciclo do Esforço Investigativo Criminal
}

\author{
Adriano Mendes Barbosa \\ Academia Nacional de Polícia - Brasil \\ 2.
}

\begin{abstract}
RESUMO
A investigação criminal para ser desenvolvida com o máximo de eficácia necessita de um norte orientador. Não é, por conseguinte, suficiente, em que pese necessária, a mera práxis investigativa criminal, sendo imprescindível uma abordagem científica através de um método que conduza os trabalhos investigativos. Uma solução pragmática e metodológica para tal mister é a aplicação do Ciclo do Esforço Investigativo Criminal (CEIC) que aborda a situação-problema do crime perpetrado desde o seu nascedouro, quando ainda representa uma notitia criminis, passando pela busca e coleta de dados da realidade fática que traduzam evidências do delito, bem como seu estudo e análise, até o estabelecimento dos elementos probatórios que retratem a autoria, materialidade e circunstâncias delituais. Com efeito, aplicando o CEIC o investigador criminal otimizará o seu labor investigativo e terá condições de melhor enfrentar a problemática da infração penal materializada no tecido social.
\end{abstract}

Palavras-Chave: Investigação. Investigação criminal. Esforço investigativo. Método. Metodologia.

\section{I - Metodologia COMO InSTRUmento SINE QUA NON DA INVESTIGAÇÃo Criminal}

A investigação criminal é de fato o centro de gravidade do estabelecimento da verdade material, aquela que mais se aproxima da realidade dos fatos e é processualmente válida, (GRINOVER, 1997) que espelha e retrata um crime sob escrutínio. Podem até alguns processualistas penais, e aqueles outros que enxergam a fase pré-processual da persecução criminal como de todo dispensável e de somenos relevância, sustentar que o edifício probatório se ergue só, e somente só, em sede processual, referindo-se ao processo como sendo o verdadeiro e único "locus amoenus" para a ascensão da prova crimi- 
nal. Todavia, também verdade é que estes mesmos ortodoxos da processualística penal nutrem apenas uma relação ascéptica, fria e distante com o nascedouro da própria prova. Em regra, estes escolásticos enxergam os elementos probatórios somente quando autuados nos autos do processo criminal, não tomando qualquer contato sensorial, e por vezes analítico e intelectual, com o fenômeno da atividade criminosa que se busca reprimir. Com efeito, tais operadores e pensadores do direito processual penal enxergam a evidência criminal através de uma espécie de binóculo jurídico-processual, que ao mesmo tempo em que os aproxima de algumas nuances das evidências que darão suporte ao vindouro edifício probatório, os mantém distante da verdade material sobre os eventos da realidade fática que serão objeto da própria ação penal. Assim, esta perspectiva distante, limitada, meio que enviesada, do processo de engendramento das provas faz com que não se enfrente uma das questões cruciais em matéria de alcance da verdade material que é o nascedouro das evidências que ensejarão o partejamento da prova que virá a lume em sede processual.

O que se realiza, por conseguinte, neste trabalho é o engendramento de uma espécie de lupa-científico-metodológica para apreender em todos os detalhes e dimensões o momento em que surgem para a realidade da vida em sociedade os elementos fáticos adstritos a um dado evento criminoso e a forma pela qual tais elementos são observados, angariados, tratados, analisados, compreendidos e carreados nos autos de uma investigação criminal para fins de estabelecimento de subsídios fáticos e jurídicos para que em juízo, sob o manto do devido processo legal, com amplas e abundantes oportunidades de defesa e contraditório, estes possam dar pálio ao nascimento da prova. Isso, por óbvio, sem se olvidar das provas que por suas características objetivas, v.g., laudos periciais, são $a b$ “initio" produzidas ainda no transcorrer da investigação criminal.

Método na antiga Grécia, “methodos” significava caminho para chegar a um fim, ou seja, um conjunto organizado de etapas a serem vencidas na investigação da verdade, no estudo de uma ciência, ou para alcançar determinado fim. Ou seja, cabe à metodologia a tarefa de percorrer os caminhos da ciência, levando o pesquisador, atuando em qualquer ramo do conhecimento humano, à reflexão que, por sua vez, levará a um emprego mais eficaz de suas formulações. Resta evidente, por via de conseqüência, a relevância do estabelecimento de um referencial e instrumental metodológicos que dê pálio ao desenvolvimento das ações investigativas. 
Ao contrario da fase "in juditio", não há no momento pré-processual da "persecutio criminis", não obstante o que é prescrito de forma lacônica no art. $6^{\circ}$ do Código de Processo Penal, como hão de ser desenvolvidos e desencadeados os atos que compõem a marcha do esforço investigativo criminal. Se não há, por conseguinte, disciplinamento legislativo regulando esta matéria, cabe a doutrina refletir sobre tais meandros e construir um caminho a se trilhar nos campos da investigação.

Hodiernamente, a investigação para ser exitosa precisa ser legal, legitima e altamente técnica, notadamente as que se debruçam sobre eventos adstritos a macro criminalidade. Outrossim, mesmo a mais alta e apurada técnica investigativa num vazio metodológico é como um grande navio que flutua sem bússola numa noite de densas nuvens onde as estrelas não se revelam. O método traz norte, luz e direção a investigação criminal, e permite ao coordenador dos trabalhos investigativos, que na seara da atuação da Polícia Investigativa (Judicial) é o Delegado de Polícia, conduzir sua equipe rumo ao objetivo da revelação da verdade material da infração penal perpetrada. Não há, portanto, como conceber a investigação criminal sem metodologia, vale dizer, sem rumo e sem trilha.

\section{II - Ciclo do Esforço Investigativo Criminal}

Neste sentido, para se levar a termo tal desiderato lanço mão de um modelo metodológico que tem o condão de melhor demonstrar como são levados a termos os quatro momentos de alta indagação para a investigação criminal e seus respectivos desdobramentos ${ }^{1}$. Tal modelo é o que chamo de

1 Veja, a propósito, o ensinamento de SENNEWALD, Charles A., TSUKAYAMA, John K. in The Process of Investigation: Concepts and Strategies for Investigators in the Private Sector. Burlington: Butterworht and Heinemann, 2001.: "An investigation is the examination, study, searching, tracking and gathering of factual information that answers questions or solves problems. It is more of an art than a science. Although the person engaged in investigation is a gatherer of facts, he or she must develop hypotheses and draw conclusions based on available information. The investigative process, that is to say, is a comprehensive activity involving information collection, the application of logic, and the exercise of sound reasoning". Continuam SENNEWALD e TSUKAYAMA, "Just as the art of investigation belongs to no one province, so no one has all the answers as to precisely how any investigation can lead to the desired solution. Too many facets are involved in the process of information collection, application of logic, and sound reasoning. Some such facets include intuition, luck, mistakes, and the often touted "gut feeling". No single textbook of formula is possible, no one book (or author) can stand alone as the ultimate authority. Our purpose, then, is an overview of investigative concepts, strategies, suggestions, guidelines, hints, and examples that can be useful to any investigator." 
Ciclo do Esforço Investigativo Criminal (CEIC). Este ciclo consegue explicitar como se dão as condutas e posturas do investigador criminal diante do delito que se investiga e a metodologia que deve ser empregada numa investigação criminal para a obtenção do resultado "ab ovo" pretendido que é a solução da situação-problema apresentada ao investigador, vale dizer, a solvência de uma infração penal, com estabelecimento da autoria, materialidade e circunstâncias relevantes adstritas ao crime sob exame. O CEIC vem ilustrado abaixo e cada um de seus momentos será devidamente explicitado nos tópicos seguintes.

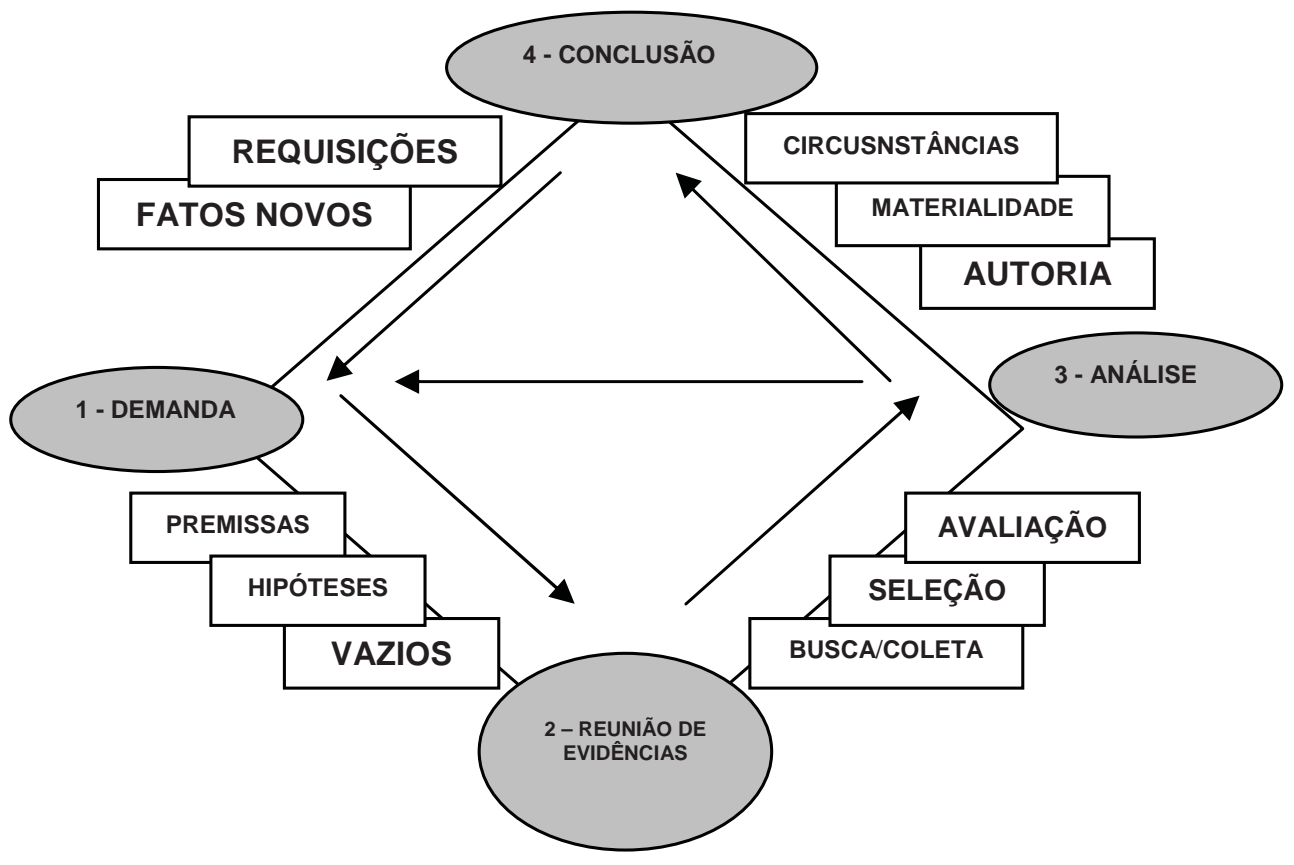

Figura didático-ilustrativa 01

Ciclo do Esforço Investigativo Criminal

\section{III - Tratamento Vestibular da Demanda INVESTIGATIVA}

Com o partejamento do fato-criminoso-gerador ascende uma demanda investigativa e cabe ao investigador sobre ela se debruça e perquirir. Esse momento é de extrema relevância para a investigação criminal, pois é o primeiro momento que o investigador toma ciência da existência da prática de uma possível ação criminosa. Há de se dizer possível ação criminosa, pois uma "notitia criminis" nem sempre traz no seu bojo a narrativa de um fato realmente criminoso. Fato corriqueiro em plantões de Delegacias de Polícia são atendimentos de cidadãos que as procuram para apresentar a notícia de 
um fato que para ele ou ela constitui, subjetivamente, uma ação criminosa; mas, que não passa de mera irregularidade administrativa ou de fato atípico, vale dizer, não-criminoso. Ou, o que é pior, a suposta "notitia criminis" pode constituir em si um delito, v.g., denunciação caluniosa, comunicação falsa de crime ou de contravenção ou auto-acusação falsa ${ }^{2}$. Assim, é de todo pertinente que quem primeiro tome ciência de uma suposta notícia do crime esteja alerta para a possível inexistência de crime a ser investigado. É com a notícia da prática de um delito que se põe em movimento a máquina estatal de persecução criminal. E para esta máquina poder alcançar os melhores resultados possíveis ela tem que superar a inércia de forma mais eficiente e eficaz.

Assim, todos os detalhes fáticos que circundam a notícia de um crime devem ser observados e registrados para futura análise por parte do investigador. Seja um ofício que lhe chegue as mãos, seja uma reportagem televisa ou escrita que lhe é apresentada, ou mesmo as declarações de uma testemunha ou vítima que o procura, o investigador há de estar atento às nuances do caso, não somente às suas cores. $\mathrm{Na}$ abordagem inicial de um crime, que se dá com o contato com a "notitia criminis", o investigador tem que agir com a cautela necessária para não se deixar seduzir por aquilo que lhe salta aos olhos. Deve ele buscar a reconstrução da história que permeia o crime praticado. Francesco Carnelutti (1995, p. 43) ensina que:

Um fato éum pedaço de história; e a história é a estrada que percorrem, do nascimento à morte, os homens e a bumanidade. Um pedaço de estrada, portanto. Saber se um fato aconteceu ou não quer dizer, portanto, voltar a trás. Este voltar atrás é aquilo que se chama fazer a bistória.

O investigador, neste sentido, reconstrói a história do fato criminoso e esta reconstrução há de ser realizada com racionalidade, sem máculas emocionais. É claro que o investigador, ser humano que é, é produto de sua própria história e, por conseguinte, forjado por emoções, valores, experiências dos mais diversos matizes. Todavia, o seu mister exige que sua atuação se dê de forma arredada do eivo da percepção subjetiva, por vezes influenciada por sentimentos de vindita ou piedade, da vítima ou da testemunha, em relação aos fatos sob exame. Aqui cabe a máxima popular que ensina que nem tudo é o que parece ser. Assim, o ofício que chega ao investigador de um órgão público comunicando a prática de um delito pode estar maculado por interesses coorporativos e/ou políticos; a reportagem que publica matéria sobre dado

2 Estes três delitos constituem crimes contra a administração da justiça e estão capitulados no CP nos art. 339, 340 e 341, respectivamente. 
esquema criminoso pode estar maquiada pelo sensacionalismo que só tem compromisso com pontos de audiência e tiragens de jornal; e a testemunha e a vítima que foram atingidas pela cena do crime podem estar afetadas de tal forma pela realidade fática do delito que suas impressões permanecem eivadas pela emoção e abalo psicológico.

Por óbvio, o investigador não há de desprezar qualquer dessas fontes de dados relativas à prática delituosa, mas ele há de abordá-las de maneira outra que não precipitada. Deve o investigador agir de forma cautelosa procurando separar o que é relacionado com os fatos e o que fruto de apreensões subjetivas que se encontram distante da realidade. Por conseguinte, o investigador há de se lançar sobre o fato sob análise escrutinando os dados da realidade que a traduzem. Neste diapasão, ele executa a busca de dados orientada pelas indagações que quando respondidas trazem solução à situação problema, vale dizer, ao suposto crime praticado. $\mathrm{O}$ investigador diante da situaçãoproblema (crime) há de indagar sobre: (a) O que aconteceu; (b) Quem foi o autor do fato; (c) Quando tal fato se deu; (d) Onde ele aconteceu; (e) Por que ele veio à tona; (f) Como foi o ato criminoso praticado; e (g) Com quais instrumentos o seu autor levou a termo a sua perpetração.

Ou seja, ele procura com tais questionamentos se aproximar da autoria e materialidade delituais, bem com das circunstâncias de lugar, tempo, modo e ânimo que são adstritos ao crime. Tais indagações são exatamente a reconstrução histórica de que sustenta Carnelutti suso citada.

Diante de tais questionamentos, que "ex surge" como forma de orientação do planejamento das ações investigativas, o investigador se deparará com as premissas, as hipóteses e os vazios relacionados com o fato criminoso. $\mathrm{O}$ escopo do investigador em face destes três elementos será a ratificação ou retificação das premissas e hipóteses e o preenchimento dos vazios. Assim sendo, se alcançarão os limites fáticos que circundam a atividade delituosa sob investigação.

As premissas constituem dados da realidade fática que são observados pelo investigador e que em princípio são verdadeiros, dentro de uma dada inferência. Vale dizer, elas são constatações emanadas do raciocínio lógico do investigador. Para melhor entendimento de como se dá o desenvolvimento do CEIC é de bom alvitre que se lance mão de um exemplo ilustrativo que traga a descrição de uma prática delituosa e a sua conseqüente investigação. Segue, então, o exemplo ilustrativo: 
A Polícia Rodoviária Federal (PRF), exercendo a sua função constitucional de policiamento ostensivo rodoviário na BR-060 realizou a apreensão de cinco notas de cinqüenta reais com algum indicativo externo de falsidade ${ }^{3}$. Tal apreensão ascendeu da ação de um policial rodoviário que realizou a abordagem de veiculo de marca esportiva e vidros com películas escuras. O policial desconfiou do comportamento dos dois cidadãos que ocupavam o carro quando da solicitação da apresentação da carteira de identidade e da habilitação do motorista do automóvel. Nesse momento o condutor do veiculo demonstrou sinais exteriores de nervosismo e inquietação com a abordagem policial. Diante destes estado de coisas o policial rodoviário de posse dos documentos pessoais do motorista realizou consulta em bancos de dados criminais disponibilizados pela Rede INFOSEG ${ }^{4}$ e detectou que o motorista possuía antecedente criminal, contando inclusive com condenação penal por formação de quadrilha e estelionato. Diante do comportamento suspeito do condutor do veiculo e da constatação de antecedentes criminais o policial rodoviário, junto com outro colega de profissão, levou a efeito uma busca veicular e pessoal nos citados cidadãos. Por ocasião da busca pessoal foram encontradas com o motorista cinco notas de cinqüenta reais. O policial rodoviário através de inspeção visual suspeitou da veracidade das notas em face da numeração seqüencial das cinco notas, marca d'água sem consistência e coloração desbotada. Com tal fundada suspeita, motorista e passageiro do veiculo foram entrevistados e passaram a negar que aquelas notas pertenciam ao condutor do veiculo e que não sabiam explicar se elas eram falsas ou verdadeiras. Diante deste cenário, foi dada voz de prisão ao motorista do veículo por prática do crime de moeda falsa ${ }^{5}$, sendo o mesmo e o passageiro encaminhados

3 Aqui não há de se especular (por não ser o locus amoenus para tanto) se a falsificação é tosca a ponto da nota falsa ser objeto material (artifício) adstrito à prática do crime de Estelionato, ex vi art. 171, caput, CP.

4 “A Rede INFOSEG tem por objetivo a integração das informações de Segurança Pública, Justiça e Fiscalização, como dados de inquéritos, processos, de armas de fogo, de veículos, de condutores, de mandados de prisão, dentre outros entre todas as Unidades da Federação e Órgãos Federais.A Rede disponibiliza informações por meio da internet em âmbito nacional, utilizando um Índice onde é possível acessar informações básicas de indivíduos. O detalhamento dessas informações é acessado, a partir de uma consulta inicial no índice, diretamente nas bases estaduais de origem, mantendo a autonomia dos estados em relação as suas informações detalhadas. A rede INFOSEG concentra em sua base de dados apenas as informações básicas que apontam para as fontes de dados dos estados, no caso das informações de processos, inquéritos e mandados de prisão". Disponível em http://www. infoseg.gov.br/infoseg/rede-infoseg/descricao (acessado em 15/10/2008).

5 Moeda falsa, art. 289. Falsificar, fabricando-a ou alterando-a, moeda metálica ou papel-moeda de curso legal no país ou no estrangeiro: Pena - reclusão, de três a doze anos, e multa. $\$ 1^{\circ}$ Nas mesmas penas incorre quem, por conta própria ou alheia, importa ou exporta, adquire, vende, troca, cede, empresta, guarda ou introduz na circulação moeda falsa. $₫ 2^{\circ}$ Quem, tendo recebido de boa fé, como verdadeira, moeda falsa ou alterada, a restitui à circulação, depois de conhecer a falsidade, é punido com detenção, de seis meses a dois anos, e multa. $\$ 3^{\circ}$ É punido com reclusão, de três a quinze anos, e multa o funcionário público ou diretor, gerente, ou fiscal de banco de emissão que fabrica, emite ou 
até a sede da Superintendência Regional da Polícia Federal no Distrito Federal, o primeiro na condição de preso em flagrante, e o segundo para prestar declaraçôes acerca do fato.

Em face desta situação o investigador ao se deparar com a "notitia criminis" do delito acima descrito tem diante de si os seguintes elementos fáticos: (a) Os depoimentos dos policiais rodoviários, condutor e testemunhas do flagrante; (b) As declarações do conduzido; (c) As declarações de um terceiro que pode estar vinculado ao evento criminoso; (d) Os antecedentes criminais do conduzido; (e) Os objetos materiais do suposto crime praticado, que consiste em cinco notas de cinqüenta reais tidas como falsas.

Por conseguinte, tal cenário traz ao investigador pelo menos duas premissas, quais sejam: (a) As notas de cinqüenta reais apreendidas são provavelmente falsas e (b) $\mathrm{O}$ conduzido tinha sob sua guarda cinco notas de cinqüenta reais provavelmente falsas.

Por óbvio, as premissas não exprimem um nível de certeza "extremis" de dúvida. Elas constituem indicativo da existência de indícios dos quais se infere que em princípio houve a prática de um ato delituoso. Com o desenvolvimento das investigações e a ascensão de todas as diligências, exames técnicos (no caso "sub examine", laudo pericial de moeda falsa) e análises criminais pertinentes, aquela premissa inicial, quando ratificada, constituirá elemento probatório que dá suporte ao estabelecimento da verdade real.

As hipóteses constituem uma suposição admissível que serve como explicação da existência de determinado fato. Estas surgem para o investigador depois da busca e colheita de dados e da conseqüente necessidade de explicação do problema posto associado a estes dados. As hipóteses em sede de investigação criminal também são chamadas de linhas de investigação que são determinadas pelo investigador quando este se depara com uma situação criminosa. São, em verdade, conjecturas engendradas pelo investigador diante do fato criminoso que lhe é apresentado.

Tendo como referência o caso de moeda falsa acima declinado, poderiam ser hipóteses, ou linhas de investigação, de tal situação: (a) o cidadão, que trazia consigo a nota de cinqüenta reais, era um incauto e não sabia da

autoriza a fabricação ou emissão: I - de moeda com título ou peso inferior ao determinado em lei; II - de papel-moeda em quantidade superior à autorizada. $\$ 4^{\circ}$ Nas mesmas penas incorre quem desvia e faz circular moeda, cuja circulação não estava ainda autorizada. 
falsidade das moedas; (b) o mesmo indivíduo é membro de uma quadrilha especializada em falsificação de moeda e o passageiro é seu parceiro no crime; (c) o indivíduo preso obteve aquelas notas através de saque num terminal bancário eletrônico; e (d) tal indivíduo recebeu as supostas notas falsas numa dada transação comercial.

Neste diapasão, diante de um delito podem surgir diversas hipóteses que explicam a sua existência, inclusive para eximir de culpa um determinado suspeito. Quando do estabelecimento das linhas de investigação deve o investigador elencar as mais plausíveis que expliquem a existência do fato criminoso. Não que se deva excluir qualquer linha de investigação "prima facie". Mas, é de bom alvitre que as hipóteses levantadas sejam de confirmação plausível e não mera conjecturação fantasiosa. No exemplo apresentado não haveria de constituir linha de investigação a suposição de que o cidadão preso na posse das notas falsas as obteve mediante doação das mesmas por parte de um terceiro estranho que o mesmo encontrou na regiáo central de uma grande cidade pátria. A hipótese há de ser plausível, pois, assim, não sendo há investimento a fundo perdido de recursos preciosos para o estado, como desperdício de horas de trabalho de mão-de-obra especializada que poderia ser empregada em situações criminosas que realmente necessitam ações investigatórias. E aqui cabe o que foi dito em relação às premissas, vale dizer, com o desenvolvimento das investigações e a ascensão de todas as diligências, exames técnicos (no caso "sub examine", laudo pericial de moeda falsa) e análises criminais pertinentes, as hipóteses estabelecidas serão ou não ratificadas. E quando ratificadas constituirão os elementos fáticos que darão suporte ao estabelecimento da verdade material.

Noutro giro, os vazios são os questionamentos fulcrais engendrados em face de um fato criminoso sob escrutínio e que carecem de respostas. Eles representam a ausência de solução ao problema posto (crime). Assim, se em uma dada investigação criminal não se consegue superar algum vazio - que é materializado através da ausência de resposta a alguma das questões: "QUIS" - quem? "QUID” - que coisa? "UBP" - onde? "QUANDO" - quando? "QUO$M O D O$ " - de que maneira? "CUR" - por quê? "QUIBUS AUXILIS" - com que auxílio? - sobre ela incidirá a mácula de ineficácia. Tais indagações compõem o chamado Heptâmetro de Quintiliano (Marcus Fabius Quitilianus). 
Cipião Martins, citado por Pery Cotta (2002, p. 66.), afirma que:

No século I, o reitor romano Quintiliano, possivelmente nascido em terras de Espanha (Calahorra), traçou em sua Instituição Oratória os precisos contornos da Retórica, mais conhecidos como circunstanciais: pessoa, fato, lugar, meios, motivos e modo.

E Conclui Martins:

Quintiliano enunciou um heptâmetro para disciplinar o discurso: quis, quid, ubi, quibus auxiliis, cur, quomodo, quando? (quem, que coisa, onde, por que meio, como, quando?).

Há de se frisar que tais questionamentos não são "numerus clausulos", constituindo um referencial ao qual podem ser agregados outras indagações. Eles constituem indagações mínimas, mas não exaurem o rol de indagações que devem ser feitas em face de um fato criminoso sob investigação. Há na doutrina processualista penal pátria menção expressa do milenar ensinamento de Quitiliano. Fernando da Costa Tourinho Filho (2001, p. 128) narra que João Mendes, ensinava já no início do século XX sobre a denúncia a ser apresentada pelo ministério público o seguinte:

A peça acusatória é uma exposição narrativa e demonstrativa. Narrativa, porque deve revelar o fato com todas as suas circunstâncias, apontando o seu autor (quis), os meios que empregou (quibus auxiliis), o mal que produziu (quid), os motivos (cur), a maneira como praticou (quomodo), olugar (ubi) e o tempo (quando).

Por óbvio, todos estes questionamentos são levados a efeito ab initio diante do fato criminoso, ainda na fase da investigação, sendo suas respostas, por via de conseqüência, estabelecidas já naquele momento de apuração.

Tendo como referência o caso de moeda falsa apresentado como exemplo ilustrativo, seriam vazios, que teriam que ser preenchidos, sem prejuízos de tantos outros, para o deslinde do caso: (a) Como se deu a apreensão da nota falsa e em que circunstâncias? Em outras palavras, onde elas estavam acondicionadas? Elas estavam junto ao corpo do cidadão preso, como em na sua carteira, em um bolso ou escondida em outro local? (b) As notas apreendidas são capazes de enganar o homem médio? (c) Por que o condutor do veículo trazia consigo as notas falsas? (d) Quais antecedentes criminais tal cidadão possui? Ou seja, quais crimes lhe forma imputados outrora? (e) Qual ligação criminosa possui o indivíduo preso? Tem ele algum link com esquemas criminosos envolvendo quadrilha ou bando, estelionato e moeda falsa? 
(f) $\mathrm{O}$ indivíduo (carona) que estava no veículo no momento da abordagem da PRF tem alguma participação na ação delituosa? (g) De onde vinha e para onde ia o cidadão preso?

Com a incidência e permanência de vazios a investigação não alcançará a solvência do fato criminoso, seja em relação à sua autoria, seja em relação à sua materialidade, ou a alguma circunstância imprescindível ao seu deslinde.

\section{IV - REUNIÃo DE EVIDÊNCIAS}

O procedimento de reunião de evidências vem à tona exatamente para angariação de elementos da realidade que têm o condão de ratificar ou retificar premissas e hipóteses, preencher vazios, e compor o cabedal de provas a ser estabelecido e legitimado sob o crivo do contraditório e da ampla defesa ${ }^{6}$ em sede de processo penal sob presidência da autoridade judicial.

A reunião de evidências é levada a efeito através do emprego de técnicas investigativas que permitem ao investigador a busca e coleta de evidências, bem como a seleção e avaliação destes elementos factuais que vão formar o cabedal de provas relacionado com o evento criminoso sob luzes. A Lei ${ }^{0}$ 9.034/1995, por exemplo, traz rol de meios operacionais para a prevenção e repressão de ações praticadas por organizações criminosas que, em verdade, constituem técnicas investigativas, como a ação controlada, a captação, acesso a informações fiscais e bancárias, a interceptação ambiental de sinais eletromagnéticos e infiltração por agentes de polícia em organizações criminosas.

Há de se registrar que, em termos genéricos, evidência ${ }^{7}$ é tudo aquilo que pode ser usado para provar que uma determinada afirmação é verdadeira

6 O Mestre José Afonso da SILVA ensina, in Comentário Contextual à Constituição, São Paulo: Editora Malheiros, 2008, p. 154, que os princípios do contraditório e ampla defesa "são dois princípios fundamentais do processo penal. O primeiro, de certo modo, já contém o segundo, porque não há contraditório sem ampla defesa, que a constituição agora estende ao processo civil e ao processo administrativo. De fato, a instrução criminal contraditória tem como conteúdo essencial a garantia da plenitude da defesa, com os meios e recursos a ela inerentes. A contraditoriedade, no processo judicial e no administrativo, constitui pressuposto indeclinável da realização de um processo justo, sem o quê a apreciação judicial de lesão ou ameaça a direito se torna vazia de sentido valorativo (...)”.

7 Ver, à propósito, o ensinamento de Jeremy BETHAM, já no século XIX, no seu Rationale of Judicial Evidence, Colorado: Rothman \& Co. Little, 1999, p. 17: By the term evidence, considered according to the most extended applications that is given to it, and seems in general to be understood. - any matter of fact, the effect, tendency, or design of which, when presented to the mind, is to produce a persuasion concerning the existence of some other matter of fact: a persuasion either affirmative or disaffirmative of its existence. 
ou falsa. Noutro giro, na seara da investigação criminal, e por via de conseguinte sob a perspectiva jurídico-penal, o que é chamado de evidência há de ser todo elemento fático que guarda alguma relação com a infração penal perpetrada e tem o condão de contribuir para a solução do problema (crime) através da composição de um bojo probatório. A evidência que se busca na investigação, por conseguinte, é o espelho da prova que se formará no corpo da ação penal.

Aqui bem cabe a lição magistral de Nicola Flamarino dei Malatesta (2005, p. 87) sobre o que vem a ser a prova em matéria criminal:

A prova é o meio objetivo com que a verdade atinge o espirito; e o espirito pode, relativamente a um objeto, chegar por meio das provas tanto à simples credibilidade, como à probabilidade e certeza. A prova, portanto, em geral, é a relação concreta entre a verdade e $o$ espirito humano nas suas especiais determinações de credibilidade, probabilidade e certeza.

Conclui o Mestre italiano:

Ora, visando-se em juizo criminal a estabelecer a realidade dos fatos, só são propriamente provas as que levam a nosso espirito uma preponderância de razões afirmativas para crer em tais realidades; e, por isso, só são propriamente provas as da probabilidade, a simples preponderância, maior ou menor, das razões afirmativas sobre as negativas e as da certeza, o triunfo das razóes afirmativas para crer na realidade do fato.

De outra margem, pode-se afirmar que há uma relação de conteúdo e continente entre evidências e provas. Isso, onde as provas são o conteúdo do continente de evidências. Vale dizer, as provas são os resultados dos ajuntamentos de evidências selecionadas, avaliadas, analisadas pelo investigador e referendadas em juízo sob os auspícios do devido processo legal. É claro, que pode haver a ascensão de provas sem necessariamente ter passado pelo CEIC. É exemplo desta situação a evidência trazida ao processo penal pelas mãos do advogado de defesa que apresenta, v.g., em juízo documentos outros que estavam em poder do réu e que por um motivo ou outro não foram alcançados pela investigação criminal pré-processual.

O Mestre Processualista Tourinho Filho (2001, p. 432) ensina que, in verbis:

Provar é, antes de mais nada, estabelecer a existência da verdade; e as provas são os meios pelos quais se procura estabelecer a existência da verdade. 
Finaliza o sábio professor:

Entendem-se, também, por prova, de ordinário, os elementos produzidos pelas partes ou pelo próprio juiz, visando a estabelecer, dentro do processo, a existência de certos fatos. É o instrumento de verificação do thema probandum.

Portanto, hão de ser consideradas evidências, na seara da investigação criminal, documentos de qualquer ordem, vestígios materiais do crime, depoimentos de testemunhas, declarações de investigados e suspeitos, etc. É claro que uma evidência pode vir a constituir uma prova, mas nem toda evidência será necessariamente uma prova. Quando em juízo, na fase processual da persecução criminal, sob o crivo do contraditório e da ampla defesa, todas as evidências apresentadas serão apreciadas pelas partes, vale dizer, ministério público, advogado de defesa, assistente de acusação, e pelo juízo na pessoa do órgão judicial que funciona no feito, seja um magistrado de primeira instância, seja um colegiado de segundo grau de jurisdição. Com a ratificação judicial das evidências, em face de sua legitimidade, legalidade e relevância estas ganham estatura de prova e passam a ser hábeis a cumprir o seu objetivo. Também é ensinamento de Tourinho Filho (2001, p. 432) de que:

Oobjetivo ou finalidade da prova éformar a convicção do Juiz sobre os elementos necessários para a decisão da causa. Para o julgar o litígio (que no processo penal se dá entre o choque do jus libertatis do réu e o jus puniendi do estado), precisa o juiz ficar conhecendo a existência do fato sobre o qual versa a lide. Pois bem: a finalidade da prova é tornar aquele fato conhecido do juiz, convencendo-o da sua existência. As partes, com as provas produzidas, procuram convencer o juiz de que os fatos existiram, ou não, ou, então, de que ocorreram desta ou daquela forma.

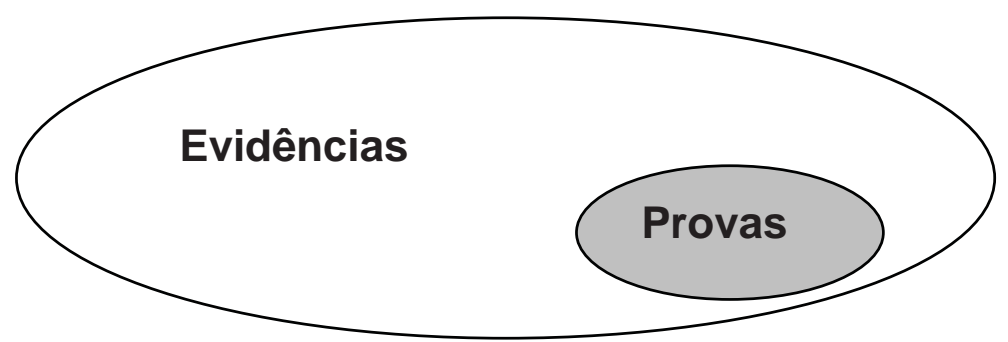

Figura didático-ilustrativa 02

Relação conteúdo continente entre provas e evidências 
A figura de dois círculos circuncêntricos, método dos diagramas de Venn ${ }^{8}$, serve como técnica gráfica para melhor entendimento da relação entre prova e evidência da seara da investigação criminal. Tal disposição demonstra que pode haver evidências que não alcançarão o status de prova, mas o conjunto de provas está inserido no de evidências.

Exemplo disso são os casos sob investigação que empregam a técnica investigativa da interceptação telefônica nos termos da Lei n ${ }^{0}$ 9.296/1996. Nestes casos vários diálogos entre investigados e entre investigados e terceiros, muitas vezes completamente alheios ao objeto da investigação, são monitorados em face de ordem judicial. Cada diálogo interceptado constitui uma evidência do esforço investigativo, contudo nem todo diálogo monitorado terá o condão de constituir uma prova. Haverá no seio de uma investigação desta estatura diálogos cifrados, declinados sob códigos, diálogos com pouca clareza e diálogos que, em que pese terem algum liame com os fatos investigados, são rarefeitos em conteúdo. Assim, diálogos deste matiz formarão o conjunto de evidências da investigação, mas não terão força probatória que os eleve à condição de prova.

A coleta é a obtenção de evidências disponíveis, isto é, de livre acesso a quem procura obtê-los. Ou seja, através da coleta se promove a arrecadação de evidências que estão ao alcance imediato do investigador sem necessidade de engendramento de esforços investigativos para superar direitos e garantias individuais ${ }^{10}$, nem emprego de técnicas investigativas operacionais. Exemplo de coleta no bojo da situação problema de moeda falsa suso declinada seria: (a) angariação da numeração da placa, chassis e número RENAVAM ${ }^{11}$ do veículo onde se encontrava o cidadão preso e seu companheiro de viagem suspeito; (b) angariação da numeração dos documentos pessoais do preso e do passageiro suspeito, com respectivas cópias; (c) consulta em bancos de dados

8 RUSKEY, Frank, WESTOM, Mark. A Survey of Venn Diagrams, Department of Computer Science University of Victoria, Victoria, B.C, Canada. Disponível em http://www.combinatorics.org/ Surveys/ds5/VennEJC.html, acessado em 23/01/2007.

9 Ordena o art. $1^{\circ}$ deste diploma normativo: a interceptação de comunicaçôes telefônicas, de qualquer natureza, para prova em investigação criminal e em instrução processual penal, observará o disposto nesta Lei e dependerá de ordem do juiz competente da ação principal, sob segredo de justiça.

10 Em relação a esses dados há de se observar incondicionalmente o que prescreve a Lex Excelsa no que concerne à proteção aos direitos fundamentais do homem, notadamente da liberdade ambulatória, inviolabilidade do domicílio, do sigilo das comunicações, etc. Neste diapasão, quando o investigador se deparar com dados que estão sob o pálio constitucional como os suso referidos ele necessitará da devida ordem judicial para os alcançar e buscar.

11 Registro Nacional de Veículos Automotores. 
sobre os documentos descritos nos itens 1 e 2 retro; (d) consulta em banco de dados sobre os indivíduos suspeitos; (e) asrrecadação e apreensão das notas supostamente falsas; (f) fotografia dos cidadãos suspeitos; (g) redução a termo das declarações do preso e do carona; (h) angariação de eventuais vestígios no interior do automóvel.

A busca, por sua vez, é a obtenção de evidências não disponíveis de maneira imediata por parte do investigador. As evidências que são objeto de busca são aqueles que estão sob o pálio de manobras protetivas do investigado, tendo em vista que as mesmas o colocam diretamente adstrito ao delito por ele perpetrado, ou aqueles outros que demandam açóes investigativas operacionais, ou são evidências que para serem alcançadas necessitam de afastamento de proteção constitucional. Exemplo de busca no bojo da situação problema de moeda falsa suso declinada seria: (a) vigilância realizada em face do cidadão acompanhante do motorista preso após a redução a termo de suas declarações na PF; (b) quebra do sigilo das comunicações do indivíduo preso; (c) fotografia operacional das pessoas suspeitas que venham a manter contato com acompanhante do motorista preso; (d) emprego de Informantes para obtenção de dados relativos ao cidadão preso e seu companheiro; (e) infiltração de agente policial em organização criminosa de que faz parte o indivíduo preso e seu colega.

Nos processos de coleta e busca é de bom alvitre que o investigador observe alguns critérios para otimização da investigação neste momento em que as primeiras evidências, e por vezes elementos de provas robustos são arrecadados. Desse modo, o investigador em relação às evidências a ser angariadas deve: (a) não desprezar nenhuma evidência mesmo que em princípio pareça insignificante; (b) não descartar evidências à vista dos mesmos poder favorecer o indivíduo suspeito; (c) partir do mais simples para o mais complexo; (d) partir do de menor custo para o mais dispendioso; (e) partir do de pouco ou nenhum risco para o mais arriscado; (f) esgotar a capacidade do próprio órgão antes de acionar outros.

A seleção consiste na triagem, exclusão, que obviamente tem aqui o significado de descarte intelectual e não de retirada física da evidência, e escolha das evidências que são de fato importantes ou de menor monta para o deslinde do caso, a partir do critério de relevância para a futura produção de prova. Com a seleção promove-se a separação do joio do trigo. Tal momento é de todo relevante tendo em vista que por ocasião da coleta e busca muitas 
evidências laterais, vale dizer, evidências que não contribuem para a direta solvência do crime, são angariadas. Exemplo de seleção no bojo da situação problema de moeda falsa suso declinada seria: (a) exclusão de conversas interceptadas dos investigados com ordem judicial que não esclarecem o crime de moeda falsa; (b) restituição de documentos pessoais dos investigados que não falsificados, com o cuidado de se manter cópia dos mesmos; (c) destaque das evidências que materializam o crime de moeda falsa, como as notas apreendidas e as declarações dos investigados e testemunhas.

A avaliação é o processo a que são submetidos as evidências para aferição da sua força "probandi" no sentido de se estabelecer se dada evidência angariada tem condições de compor o futuro cabedal probatório. Isso, tanto do ponto de vista do mérito da investigação, quanto do seu aspecto legal. É a partir deste momento, portanto, que se agiganta a intervenção do profissional da investigação versado em Ciências Jurídicas. No caso da investigação criminal conduzida pela Polícia Judiciária, o Delegado de Polícia deve intervir neste momento do CEIC para emprestar uma leitura jurídica às evidências colocando-as sob o crivo da legalidade e legitimidade. Por óbvio, na investigação policial o Delegado de Polícia, como coordenador dos trabalhos investigativos, atua em todos os momentos do CEIC na condição de profissional da investigação criminal, assim, como agentes de polícia e peritos criminais. Mas por ocasião da fase da avaliação a sua condição de operador do direito é de maior relevo, pois a partir deste momento do Ciclo do Esforço Investigativo Criminal há os primeiros passos definitivos para a constituição daquilo que no futuro será a prova.

\section{V - ANÁlise das Evidências Angariadas}

O momento da análise promove a associação, cruzamento e valoração das evidências para fins de estabelecimento daquelas que formarão o rol das provas a serem apresentadas por ocasião da conclusão das investigações ao "dominus litis" da ação penal para oferecimento de denúncia. A análise que se promove na investigação criminal é a análise criminal, mais especificamente a análise criminal tática ${ }^{12}$. Em prol da análise, serão empregados

12 Ver, a propósito, o que sustenta a International Criminal Police Organization (INTERPOL), disponível em http://www.interpol.int/Public/CIA/Default.asp (acessado em 21/10/2008), in literis: "Criminal Intelligence Analysis is divided into operational (or tactical) and strategic analysis. The basic skills required are similar, and the difference lies in the level of detail and the type of client to whom the products are aimed. Operational Analysis aims to achieve a specific law enforcement 
tanto a Lógica ${ }^{13}$, já utilizada pelo investigador desde o estabelecimento das premissas e hipóteses, quanto ferramental tecnológico como softwares de análise criminal, como o "i2 Analyst's Notebook"14. Em verdade a análise se dá a todo momento da investigação, não havendo um momento estanque onde se somente acontece a análise das evidências.

Mais ainda, as fases do CEIC não estão divididas em compartimentos incomunicáveis e herméticos. O processo de investigação é dinâmico e não comporta o confinamento de suas fases a momentos fixos e específicos. É claro que metodologicamente, e do ponto de vista didático, há o estabelecimento de fases, vale dizer momentos, da investigação criminal. Outrossim, isso não significa que estas aconteçam de maneira isolada e distanciada uma das outras e que não haja o desenvolvimento de ações típicas de uma fase no bojo da outra.

$\mathrm{Na}$ análise há, por conseguinte, a promoção do estudo pormenorizado do conjunto de evidências angariado. Isso, numa perspectiva individual e global concomitantemente do conjunto de evidências arrecadadas. Assim, cada evidência é analisada individualmente e confrontada com as demais numa perspectiva micro e macro da investigação, conferindo uma apreensão da realidade fática atrelada ao crime que é traduzida através das evidências colecionadas. Exemplo de análise no bojo da situação problema de moeda falsa

outcome. This might be arrests, seizure or forfeiture of assets or money gained from criminal activities, or the disruption of a criminal group. Operational Analysis usually has a more immediate benefit. Strategic Analysis is intended to inform higher level decision making and the benefits are realized over the longer term. It is usually aimed at managers and policy-makers rather than individual investigators. The intention is to provide early warning of threats and to support senior decisionmakers in setting priorities to prepare their organizations to be able to deal with emerging criminal issues. This might mean allocating resources to different areas of crime, increased training in a crime fighting technique, or taking steps to close a loophole in a process."

13 Aqui refere-se a Lógica como ramo da Filosofia, sendo as premissas e hipóteses seus frutos.

14 Sobre o programa de análise criminal Analyst's Notebook da empresa i2 há: "Investigations typically involve large amounts of raw, multi-formatted data gathered from a wide variety of sources. Somewhere in this data lies the key to the investigation but it can remain obscured by the volume and apparent randomness of individual facts. i2 Analyst's Notebook 7 is i2's award winning visualization and analytical product which enables analysts and investigators to visualize large amounts of disparate information and turn it into meaningful intelligence. This is achieved by providing a framework for information which helps the analyst to quickly create a chart of objects and relationships. Analyst's Notebook also provides users with the tools they require to navigate, search and analyze the wealth of information contained in a chart. This allows intelligence data to be collated and filtered so that the important relationships within the investigation can be easily understood. Analyst's Notebook is considered an essential tool for intelligence and investigative analysts around the world. Proven in defense, law enforcement and commercial organizations, it has become a de facto standard for the exchange of intelligence information between agencies." Disponível em http://www.issafrica.co.za/ docs/Analyst's\%20Notebook/Datasheets/i2\%20Analyst's\%20Notebook\%207\%20Lowres\%20 Datasheet.pdf, (acessado em 21/10/2008). 
"suso" declinada seria: (a) cruzamento das evidências angariadas pelas diversas técnicas de investigação empregadas em face dos alvos, v.g., vigilância e fotografias operacionais; (b) estabelecimento das associações criminosas dos investigados na seara da falsificação de moeda e outras atividades criminosas; (c) ponderação da força probatória das evidencias colecionadas em face da investigação desenvolvida.

Com a concretização da análise de evidências o investigador vai se deparar com duas situações, a saber: (a) as evidências angariadas são suficientes para se apontar a materialidade, autoria e as circunstâncias relevantes do crime sob escrutínio; (b) o conjunto de evidências analisadas ainda aponta para a existência de vazios de tal monta que interferem no estabelecimento da verdade material.

Em sendo suficientes as evidências, o CEIC segue seu curso rumo à fase de conclusão das investigações com indicativo das evidências que vão formar as provas em juízo. Outrossim, se ainda resta indagações, relevantes às investigações, do Heptâmetro de Quintiliano a serem sanadas ascende uma nova demanda investigativa que vai ensejar o aparecimento de novas premissas e hipóteses e de nova reunião de evidências mediante busca, coleta, seleção e avaliação. Assim, se formará um sub-ciclo dentro CEIC que compreende as fases da análise com engendramento de nova demanda e necessidade uma outra reunião de evidências a serem postas a análise criminal. Esse sub-ciclo do CEIC pode ser isolado graficamente da seguinte forma:

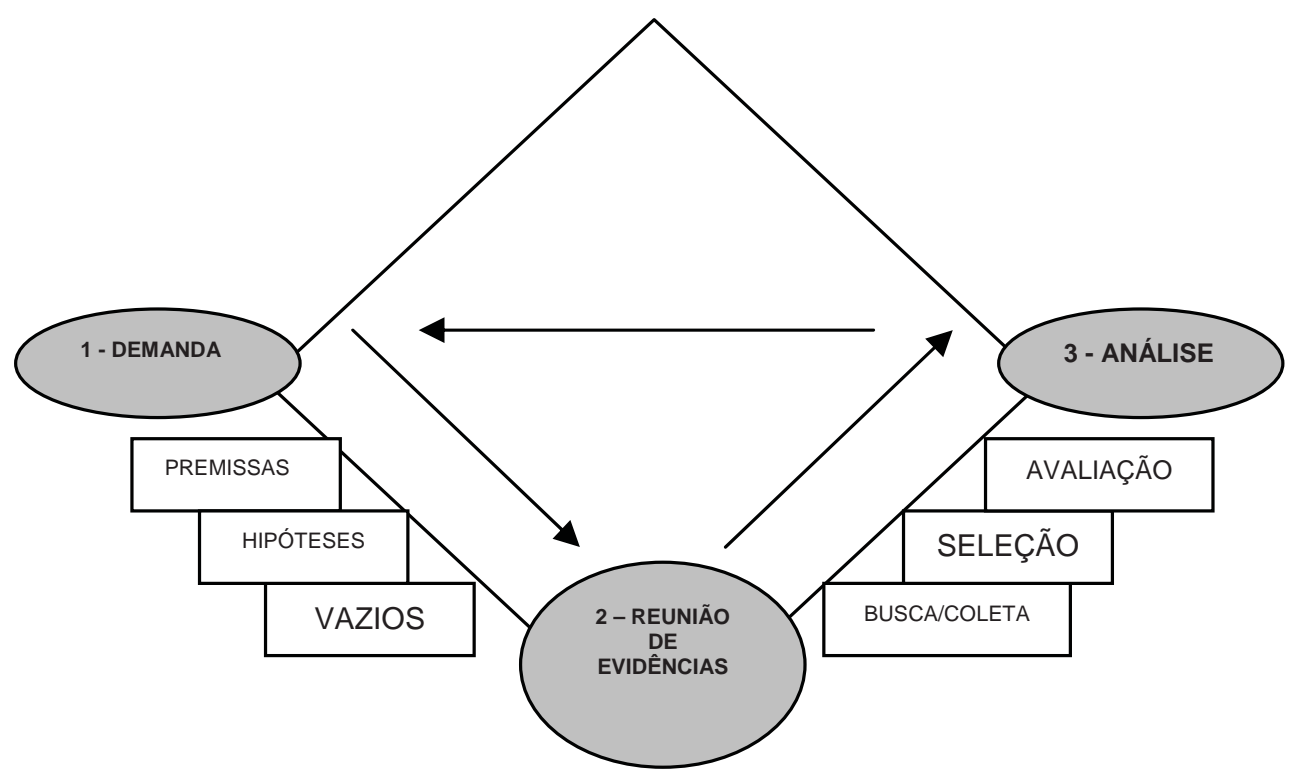

Figura didático-ilustrativa 03

Sub-ciclo da nova demanda investigativa em face da análise das evidências. 
Superada a fase da análise com a consolidação das evidências que formarão o futuro conjunto probatório parte-se para a conclusão do ciclo do esforço investigativo engendrado. Nesta fase final também se agiganta a ação do investigador com formação jurídica, ou assessorado por profissional com tal habilidade, para a produção do relatório final das investigações apontando a autoria, a materialidade e todas as circunstâncias de relevo que compõem o crime do ponto de vista fático ${ }^{15}$. Esta figura, do investigador com formação jurídica, é lugar comum nas polícias judiciárias onde há a atuação do Delegado de Polícia, que além de apreciar juridicamente o fato criminoso sob investigação também coordena os trabalhos investigativos.

Em verdade, pode-se afirmar que a ação criminosa para fins de apuração investigativa apresenta três dimensões. É claro que o fenômeno social do crime pode ser apreciado sob diversas perspectivas, como, por exemplo, a Sociológica, Antropológica, Psicológica, Criminológica e a Jurídica. Neste diapasão, o delito também pode ser apreciado sob uma perspectiva Investigativa ${ }^{16}$. Ou seja, o crime pode ser apreciado e compreendido sob o ângulo daquele que tem como ofício o desnudar e esclarecer as ações criminosas que tanto esgarçam o tecido social. Assim, o investigador criminal o aborda, avalia e analisa o crime sob uma perspectiva tridimensional que compreende a sua materialidade, autoria e circunstâncias que sobre si incidem e lhe emprestam cores e nuances. Por ser adepto da contemplação das múltiplas inteligências humanas (GARDNER, 1993) e entre estas o reconhecimento da relevância da Inteligência visual-espacial - que se desenvolve a partir de um apuramento das percepções sensoriomotoras, que permitem uma boa discriminação, entre outras coisas das formas, das dimensões e das relações espaciais - trago ao leitor mais uma figura didático-ilustrativa representando a perspectiva

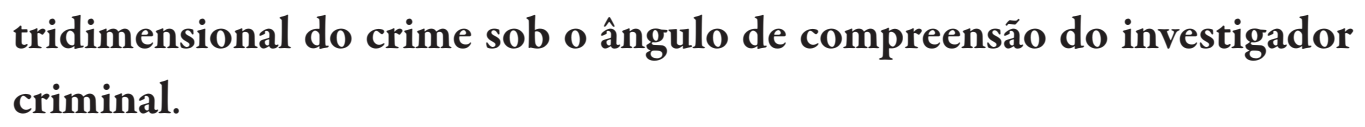
tridimensional do crime sob o ângulo de compreensão do investigador criminal.

15 Aqui não será enfrentada a questão do conceito jurídico de crime, seja formal, seja material ou legal. A compreensão de crime que deve ser trazido à baila nesta obra sobre investigação criminal é do ponto de vista do pragmatismo fático. Isso, pois aqui se fala em desnudamento do fato criminoso e não de sua apreensão jurídica em sentido estrito.

16 Há de se ressaltar que em que pese a relevância do conceito jurídico de crime, seja formal, material, analítico ou legal, o que se pretende revelar nestas páginas é uma concepção metajurídica do fenômeno criminoso que vai além da ciência jurídica e do direito positivado. Não obstante, e quase que contraditoriamente, devido à robustez dos estudos desenvolvidos pela ciência do Direito Penal esta acaba constituindo um dos principais referenciais para o entendimento do crime sob a ótica do investigador criminal. 


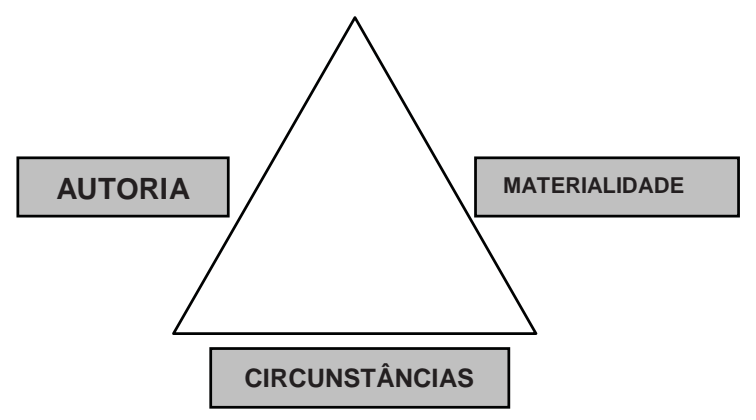

Figura didático-ilustrativa 04

Perspectiva investigativa tridimensional do crime.

A autoria ${ }^{17}$ de uma ação criminosa diz respeito ao sujeito ativo que leva a termo um delito, vale dizer, a pessoa ou pessoas, físicas ou jurídicas ${ }^{18}$, que perpetraram uma ação criminosa, praticando o núcleo verbal descrito no tipo elencado na lei penal incriminadora, ou aderindo de qualquer forma à prática desta ação criminosa. $\mathrm{O}$ investigador, então, põe-se a perseguir aquele que desenvolveu, direta ou indiretamente ${ }^{19}$, a conduta comissiva ou omissiva, que se subsume ao prescrito na lei penal incriminadora, ou aquele que de alguma forma concorreu para a perpetração do crime ${ }^{20}$. Guilherme Souza Nucci (2007, p.165) ensina que sujeito ativo, "é pessoa que pratica a conduta descrita pelo tipo penal. Animais e coisas não podem ser sujeitos ativos de crimes, nem autores de ações, pois lhes falta o elemento vontade". De outra margem, Cezar Roberto Bitencourt (2008, p. 419) leciona, in verbis, que:

O conceito de autoria não pode circunscrever-se a quem pratica pessoal e diretamente a figura delituosa, mas deve compreender também quem se serve de outrem como "instrumento" (autoria imediata). É possivel igualmente que mais de uma pessoa pratique a mesma infração penal, ignorando que colabora na ação de outrem (autoria colateral), ou então, consciente e voluntariamente, coopere no empreendimento criminoso, quer praticando atos de execução (coautoria), quer instigando, induzindo ou auxiliando (participação) na realização de uma conduta punivel.

17 Segundo o escólio de Fernando da Costa TOURINHO FILHO, op.cit. p. 57, a finalidade do inquérito policial, aqui compreendido em sentido amplo alcançando a investigação criminal como um todo, é " apurar a autoria significa que a autoridade policial deve desenvolver a necessária atividade visando a descobrir, conhecer o verdadeiro autor do fato infringente da norma”.

18 Vide arts. $173, \S 5^{\circ}$ e $225, \S 3^{\circ} \mathrm{da}$ Carta Magna.

19 Aqui faz-se referência a autoria mediata onde o autor realiza a ação criminosa por intermédio de pessoa outra inimputável ou que age sob coação irresistível ou erro.

20 Isso, nos moldes do concurso de pessoas englobando a co-autoria e a participação, nos termos do art. 29 do CPB. 
A autoria da situação problema de moeda falsa acima apresentada recairia por sobre: (a) o detentor das moedas por ocasião de sua prisão; (b) o cidadão que o acompanhava no veículo por ocasião da abordagem da PRF, isso se restar provado que os mesmos agiram em concurso ou se este indivíduo aderiu de alguma forma à conduta delituosa do portador da moeda falsa; (c) os eventuais membros da quadrilha de falsificação de moeda que fazem parte o detentor das cédulas falsificadas e o comparsa que o acompanhava por ocasião de sua prisão.

Por sua vez, materialidade consiste nos vestígios materiais dos crimes, vale dizer, nos elementos materiais que indicam a existência no mundo real do delito praticado. A materialidade traduz em termos factuais a infração penal levada a efeito. Por óbvio, há crimes que não promovem modificação no mundo exterior. Tais crimes são os designados como (a) formais e (b) de mera conduta. Para tais crimes é suficiente para as suas existências a ação do sujeito ativo e o elemento volitivo em prol da sua concretização, são exemplos de tais infrações penais a Injúria verbal, art. 140 do CPB, e a Desobediência, art. 330. Damásio de Jesus (1995, p. 168) leciona, in literis que "no crime de mera conduta o legislador só descreve o comportamento do agente. Exs.: crime de violação de domicílio (art. 150)." E conclui o Mestre Paulista afirmando que "no crime formal o tipo menciona o comportamento e o resultado, mas não exige a sua produção para a consumação. Exs.: ameaça, divulgação de segredo."

A materialidade do crime é estabelecida através da realização de exames periciais nos vestígios deixados pelo crime. Mais ainda, em relação aos crimes materiais é imprescindível a realização de exame pericial, seja direto, seja indireto, nos vestígios materiais do crime ${ }^{21}$. Exemplo de exame pericial indireto seria a análise de registros fotográficos e filmagens feitos sobre os vestígios do delito sob escrutínio. Por óbvio a regra da imprescindibilidade da realização da perícia admite exceção. A exceção óbvia é a dos casos de crimes materiais que têm seus vestígios arredados por completo pelo perpetrador da ação criminosa. Ou seja, situações em que o autor do fato toma medidas assecuratórias do êxito de sua atividade criminosa eliminando in totum os vestígios materiais do crime. Isso, para afastar a possibilidade do Estado alcançá-lo em sede de persecução criminal, seja extra juditio, seja processual. Nestes casos, elementos outros de prova que não o exame pericial poderão, em princípio, a depender da sua ro-

21 Vide art. 158 e seguintes do CPP. 
bustez suprir a ausência dos vestígios. Com efeito, provas de estatura subjetiva como depoimentos de testemunhas ${ }^{22}$ têm agigantado o seu papel no esforço do estabelecimento da existência material sob investigação.

A materialidade da situação problema de moeda falsa seria constituída pelo conjunto de notas de Real falsificadas que estavam na posse do indivíduo preso e que foram apreendidas. Em face destas notas se daria exame pericial para se comprovar a falsidade inclusive determinando se a falsidade seria ou não grosseira, fato que pode inclusive implicar na alteração da capitulação do crime sob investigação do art. $289 \mathrm{CPB}$ para o art. $171 \mathrm{CPB}$.

Por fim, é possível afirmar que as circunstâncias do crime sob a perspectiva da investigação criminal coincidem e ao mesmo tempo vão além das circunstâncias do crime contempladas no art. 59 do CPB. Isso, não em relação às circunstâncias judiciais que englobam todo o dispositivo legal, mas sim às circunstâncias stricto sensu que dizem respeito as condições relevantes de tempo, lugar, ocasião, modo, motivação, comportamento vitimal, contextos social e econômico que circundam ou acompanham o fato criminoso. Segundo o escólio de Damásio (1995, p. 479), expressis verbis, "circunstância deriva de circum stare, 'estar em redor'. Tratando-se crime, circunstância é todo fato ou dado que se encontra em redor do delito. É um dado eventual, que pode existir ou não, sem que o crime seja excluído." O desnudamento de tais circunstâncias é de extremo relevo, pois tem o condão de fazer incidir sobre o tipo penal que se amolda à conduta criminosa sob investigação atenuantes, agravantes, qualificadoras, causas de aumento ou diminuição de pena. A constatação das mesmas podem inclusive implicar na reclassificação do delito. Neste sentido, ao investigador criminal apontar a autoria e a materialidade do crime é necessário, mas não é suficiente. É preciso ir além das cores fortes que tingem o cenário criminoso da infração penal. É necessário que se busque as nuances do objeto de investigação, indo além do superficial e imediato, alcançando o que há de profundo e profícuo na tela em que está expresso o delito.

\section{VI - Conclusão das InVESTigações}

Uma vez que os elementos de autoria, materialidade e circunstâncias do crime estão todos reunidos ou restou estabelecido que é impraticável o estabelecimento de quem foi o autor do crime ou de sua própria existência alcança-se a fase de conclusão da investigação. Nesta fase o responsável pelas

22 Ex vi art. 167 do CPP. 
investigações, no caso da investigação policial a Autoridade Policial, engendra o relatório final das investigações. Tal relatório trará em seu bojo, entre outros pontos: (a) o histórico dos fatos sob investigação; (b) o rol das diligências investigativas engendradas mais relevantes; (c) a indicação do autor do crime e os elementos de evidência que sustentam esta indicação; (d) a materialidade delitual, dados da realidade que demonstram a existência do crime, e os elementos de evidência que dão lastro à existência do crime; (e) as circunstâncias que tocam o crime e (f) a capitulação, mesmo que provisória para o titular da ação penal, do delito ou delitos sob investigação.

Noutro giro, se não foi possível estabelecer autoria e materialidade o responsável pela investigação informará fundamentadamente as razões pelas quais não houve possibilidade de apontar o sujeito ativo do crime ou sua existência material.

Há de se ratificar que a investigação criminal não se dá tão somente para angariar evidências da existência do crime e sua autoria. Ela também serve exatamente para afastar possíveis autorias criminais e supostas ocorrências delituosas. O Investigador não pode ser guiado pela idéia fixa de apontar autorias criminais como numa caça a bruxas colocando na fogueira os suspeitos e envolvidos na prática delituosa. A ética e a técnica devem prevalecer em todo momento da investigação inclusive naquele em que, por ausência de evidências, têm se que se reconhecer a impossibilidade fática de se apontar o sujeito ativo da atividade delituosa ou mesmo a própria existência do delito.

Não obstante, por vezes, no labor do dia-a-dia, o investigador criminal, em face de algum vestígio, angariado nos primeiros passos do CEIC, que indique a possível participação de um investigado numa ação criminosa, se volta para buscar tudo quanto seja necessário para ratificar aquela primeira impressão (hipótese inicial). Entretanto, a Investigação Criminal se presta, também, para buscar elementos que afastem a possibilidade da existência do crime e sua autoria. Tudo isso com lastro numa investigação isenta, imparcial a que tem direito todo cidadão. Essa abordagem ética e técnica da Investigação Criminal confere a ela própria, por via de conseqüência, mais legitimidade, credibilidade e segurança jurídica, aqui em relação aos investigados, quando por exemplo o investigador em seu relatório final aponta como autor do crime sob exame um dado cidadão. 
De outra margem, não se pode olvidar que com a nova tábua axiológica imposta pela Lex Excelsa de 1988 há um impulso para que seja tomada uma postura no sentido de harmonizar diplomas legais e procedimentos, sejam de estatura administrativa, seja de estatura judicial aos princípios constitucionais, a partir do ideal de justiça e igualdade substancial. Essa nova ordem, por óbvio, atinge também todos os meandros singrados pela Investigação Criminal, que há de submeter aos ditames do Estado Democrático de Direito.

Diante deste cenário constitucional mister se faz trilhar por meandros que arredam da seara da investigação criminal todo e qualquer procedimento atentatório a direitos e garantias constitucionais mesmo que isso implique em concluir uma investigação sem se chegar ao autor do crime, fato que em certa medida "frustra" todo e qualquer investigador criminal.

Todavia, com a conclusão formal das investigações não se pode dizer extremis de dúvida que esta se encontra de forma peremptória findada. Dois eventos podem surgir após a conclusão das investigações por parte do investigador. Primeiro pode haver a ascensão de fatos novos que dão ensejo a uma nova demanda investigativa em relação ao mesmo objeto dantes investigado. Assim, a investigação pode ser reaberta diante de uma testemunha pode ser trazida à lume para prestar declarações, de um certo vestígio antes ignorado pelos peritos que agora vem à baila, de uma confissão de um delinqüente arrependido ${ }^{23}$. Segundo, o titular da ação penal, vale dizer o "Parquet" que é o titular da ação penal pode entender que são necessárias novas diligências investigativas para que forme a sua "opinio delicti" e assim tenha condições de oferecer denuncia em desfavor dos investigados ou pugnar pelo arquivamento das investigaçóes por ausência de evidências que apontem a autoria ou materialidade delitual. Por óbvio, tal se dá quando não é o próprio Ministério Público (MP) que conduz as investigações.

Neste diapasão, pode o MP requisitar novas diligências investigativas, situação que surge para o investigador como uma nova demanda investigativa a ser trabalhada. A novidade neste momento é que devido ao membro do MP ter requisitado novas diligências investigativas este deve por ocasião

23 Esse último fato inclusive já ocorreu em face do autor que já tiveram a oportunidade de relatar dado inquérito policial sem ter conseguido apontar a autoria criminal e dias depois aparecer na Delegacia de Polícia o autor do crime, que já tinha sido ouvido mas sem ter contra si provas suficientes para indiciação, para confessar a autoria do delito perpetrado em face de um arroubo de crise de consciência. 
da requisição especificar quais são as evidências que devem ser objeto de busca por parte dos investigadores. Requisições genéricas como do tipo "as testemunhas e investigados devem ser acareados" ou "devem ser ouvidas tais e tais testemunhas" não são pertinentes. Estes tipos de demanda servem tão somente para movimentar o aparato investigativo do estado, em certa medida, de forma inócua. Por conseguinte, se o "Parquet" requisita novas diligências investigativas este deve deixar bem claro aos investigadores o que ele necessita em termos de dados e evidências para superar as suas dúvidas ou hesitações, seja para o oferecimento da denúncia, seja para requerer o do arquivamento das investigações. Assim não sendo, haverá tão somente trabalho investigativo estéril, pois o investigador, que levará a termo as novas diligências, sem orientação daquele que as requisita, o fará sob a perspectiva de seu próprio entendimento sobre o caso. Neste diapasão, as evidências estabelecidas em face do novo esforço investigativo mais uma vez não serão hábeis a dar pálio ao entendimento do titular da ação penal quanto ao que este vislumbra que deve ser necessário para formação de sua "opinio delicti".

É lógico, que postura clara e pró-ativa é também pertinente quando as investigações são conduzidas por órgãos judiciais e executadas por investigadores notadamente policiais. Dessa forma, deve o responsável pela investigação, seja Ministro, Desembargador ou Juiz, por ocasião da determinação da baixa dos autos para diligências investigativas dizer o que se quer com tais diligências. Se a autoridade judicial não informa o que entende como necessário para suprir os vazios da investigação que ela própria conduz, o investigador, que ascende no cenário deste tipo de investigação como mero executor, realizará as diligências investigativas tendo como referencial o seu próprio entendimento sobre o caso sob escrutínio. O que resulta disso são as infindáveis idas e vindas dos autos que materializam a investigação.

Com essas duas situações completa-se o Ciclo do Esforço Investigativo Criminal que se origina a partir de uma certa demanda criminal e pode ter um refluxo, mesmo após sua conclusão formal, para uma nova situação que faz ciclar as ações investigativas levadas a efeitos para se estabelecer a verdade material, vale dizer a verdade mais verossímil e que melhor traduz o que factualmente ocorreu no cenário, em princípio, criminoso posto sob análise do investigador. 
Adriano Mendes Barbosa

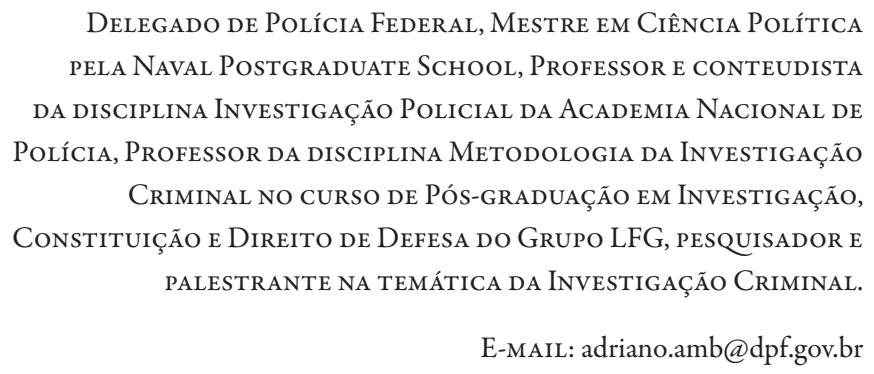

\section{REFERÊNCIAS}

BETHAM, Jeremy. Rationale of Judicial Evidence, Colorado: Rothman \& Co. Little, 1999.

BITENCOURT, Cezar Roberto. Tratado de Direito Penal, São Paulo: Saraiva, 2008.

CARNELUTTI, Francesco. As Misérias do Processo Penal, Tradutor CARDINALLI, José Antônio, São Paulo: Conan,1995.

COTTA, Pery. Aristóteles, o pai genético do Jornalismo, Comum, V.7, No 19, Rio de Janeiro, 2002.

GARDNER, H. Frames of Mind: The Theory of Multiple Intelligences. London: Fontana Press, 1993.

GRINOVER, Ada Pellegrini; FERNANDES, Antonio Scarance; GOMES FILHO, Antonio Magalhães. As Nulidades no Processo Penal. ed. Revista dos Tribunais, São Paulo,1997.

JESUS, E de Damásio. Direito Penal, 1º Volume, São Paulo: Saraiva, 1995.

MALATESTA, Nicola Flamarino dei. A Lógica das Provas em Matéria Criminal, Campinas: Bookseller, 2005.

NUCCI, Guilherme de Souza. Manual de Direito Penal, ed. Revista dos Tribunais, São Paulo-SP, 2007.

SENNEWALD, Charles A., TSUKAYAMA, John K. The Process of Investigation: Concepts and Strategies for Investigators in the Private Sector. Burlington: Butterworht and Heinemann, 2001 
SILVA, José Afonso da. Comentário Contextual à Constituição, São Paulo: Editora Malheiros, 2008.

TOURINHO FILHO, Fernando da Costa. Manual de Processo Penal, São Paulo: Saraiva, 2001.

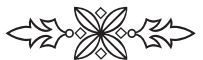

